\title{
Iran refuses to cooperate with atomic agency
}

The International Atomic Energy Agency (IAEA) last week completed a long-awaited report that was expected to wrap up its investigation of Iran's nuclear programme. But the report has failed to make progress on the two major sticking points.

According to sources close to the inquiry, the IAEA is keen to close the Iran file, but on two conditions. One is that Iran comes clean on any past weapons work. The other is that it agrees to the 'additional protocol' to the IAEA safeguards agreement, which gave extra powers to the IAEA in 1997, such as short-notice inspections of any site the agency wants to visit. This would give the IAEA greater confidence in being able to detect any clandestine facilities and operations.

Iran has not ratified the additional protocol, and although it voluntarily allowed broader inspection access from May 2004, it stopped doing so in January 2006. According to the report, released on 22 February, Iran has recently opened some sites to the IAEA, but the agency's director-general Mohamed ElBaradei says that this is "not, in my view, sufficient". He adds that the additional proto$\mathrm{col}$ is "key for us to start being able to build progress in providing assurance that Iran's past and current programmes are exclusively for peaceful purposes".

But Iran is playing hardball. It told the agency that it would comply with the additional protocol only "if the nuclear file [on Iran's nuclear capabilities] is returned from the security council to the IAEA". Iran has also refused to comply with repeated calls by the United Nations Security Council - backed up with economic and political sanctions - to halt its uranium enrichment (see Nature 451, 750-751; 2008).

On the question of past suspect activities, the IAEA report says that it considers several to be "no longer outstanding". These include work on polonium-210 and the Gchine uranium mine, which the military was suspected of being involved in running. The report adds, however, that for each issue cleared, it was still seeking "corroboration of its findings and to verify this issue as part of its verification of the completeness of Iran's declarations".

But on the major item of allegations of direct nuclear weapons work, the report says that the IAEA "still awaits" adequate responses from Iran. These include details about the 'Green Salt' project, named after the common name of uranium tetrafluoride $\left(\mathrm{UF}_{4}\right)$, a key intermediate in the production of uranium hexafluoride $\left(\mathrm{UF}_{6}\right)$ for enrichment. It was part of an illicit project that the US Central Intelligence Agency says was described in a laptop computer it obtained in Iran, and that also described a possible clandestine processing plant and military connections, including tests related Iran is playing to nuclear weapons and missiles. hardball." In meeting with Iran from 3 to 5 February, the IAEA confronted it with new intelligence information relating to high-voltage detonators and an "explosive testing arrangement that involved the use of a 400metre shaft and a firing capability remote from the shaft by a distance of 10 kilometres". The report says that the IAEA believed both "would be relevant to nuclear weapon R\&D”. Iran says the intelligence documents are fabricated. Declan Butler

\section{First chapter of book of life goes live}

The ambitious Encyclopedia of Life project published its first web pages on Earth's biological diversity on 26 February - one species per page.

Born of a 2003 essay by biologist Edward $\mathrm{O}$. Wilson and formally announced in May 2007, the website (http://eol.org) aims to create an extensive, expert-created page for each of Earth's 1.8 million named species (see Nature 449, 23; 2007). Many of the world's foremost natural-history institutions are participating.

Most of the 1 million pages set up so far are placeholders with minimal information. Around 30,000 of them are fuller, thanks to pre-existing online databases that have agreed to share their data, including the Solanaceae Source website, FishBase and AmphibiaWeb. And 24 'exemplar pages', which are rich in information and multimedia content, show how the pages will eventually look.

The project has no new funding beyond that announced last year: US $\$ 2.5$ million from the Alfred P. Sloan Foundation in New

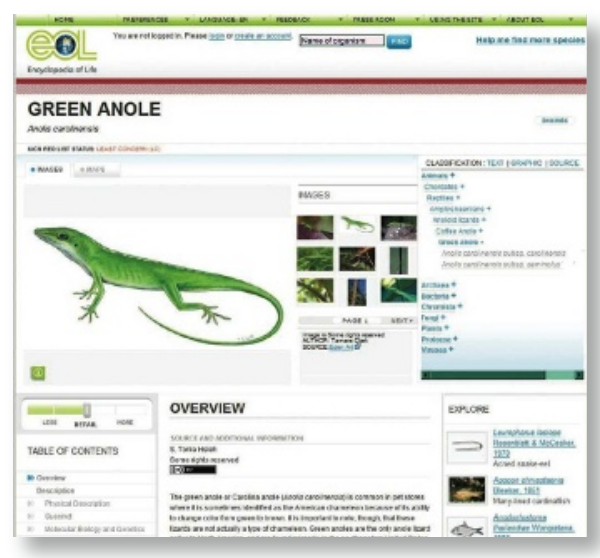

A sample page from the Encyclopedia of Life.

York and \$50 million from the John D. and Catherine T. MacArthur Foundation in Chicago, Illinois. More will be needed if the project is to meet its goal of a full page for every species by 2017 .

Executive director James Edwards says the project's biggest challenge is "providing incentives for the scientific community to participate". He is working on ways to make the pages similar to conventional publications so that academics will be credited for their input. Each page will have its own digital object identifier, and publications that cite the pages will be able to be tracked. Citations of the pages will contribute to the author's publication record.

Edwards admits that money could be problematic. "Another challenge further down the road will be to implement a financial model that will assure long-term sustainability," he says.

In the past, critics have noted that because the costs of maintaining and updating vast online databases never end, the projects tend to peter out when the funders lose interest. Sustaining their excitement about the encyclopedia for a full decade will be difficult.

The first batch of pages was officially launched this week at the TED (Technology, Entertainment, Design) conference in Monterey, California.

Emma Marris 